\title{
Electrochemical Synthesis of Mg-doped ZnO Nanotapers as Photocatalyst for Degradation of Bisphenol under Solar Light Irradiation
}

\author{
Min Wang ${ }^{1}$, Shaochun Yuan ${ }^{1,2, *}$, Bo Lv $^{2, *}$, Huaxian Yang ${ }^{3}$ \\ ${ }^{1}$ School of River and Ocean Engineering, Chongqing Jiaotong University, Chongqing, 400074, PR \\ China \\ ${ }^{2}$ Engineering Research Center for Sponge City Construction of Chongqing, Chongqing, 400020, PR \\ China \\ ${ }^{3}$ Southwest Municipal Engineering Design \& Research Institute of China, Chengdu, 610081, PR \\ China \\ *E-mail: yuansc@cqjtu.edu.cn(Shaochun Yuan) and haimiancq@163.com(Bo Lv)
}

doi: $10.20964 / 2021.02 .56$

Received: 23 October 2020/ Accepted: 19 December 2020 / Published: 31 December 2020

\begin{abstract}
This paper released electrochemical synthesis of $\mathrm{Mg}$ doped $\mathrm{ZnO}$ nanotapers for degradation of bisphenol A (BPA) as toxic aquatic pollutant under UV and visible light irradiations. The pure and $\mathrm{Mg}$-doped $\mathrm{ZnO}$ nanotapers photo-catalysts were prepared through an electrical field assisted method. The morphological, structural and optical properties of samples were characterized through the SEM,XRD and UV-Vis absorption spectra, respectively. The morphological and structural studies exhibited that the high density of pure and doped $\mathrm{ZnO}$ nanostructures were grown in vertically aligned taper-like shape and hexagonal wurtzite structures. Moreover, the doping process led to creation of the cubic $\mathrm{MgO}$ structure in $\mathrm{ZnO}$ nanotaper with (111) and (220) planes. The optical characterizations showed that the higher absorption peak was observed for doped samples due to the creation of oxygen deficiency and defects in grain structure of film. The $E_{\mathrm{g}}$ values were obtained $3.48 \mathrm{eV}$ and $3.09 \mathrm{eV}$ for pure $\mathrm{ZnO}$ and $\mathrm{Mg}$-doped $\mathrm{ZnO}$ nanotapers films, respectively. The electrochemical studies by $\mathrm{CV}$ and EIS techniques showed the improvement of specific capacitance of electric double layer and film's conductivity by $\mathrm{Mg}$ doping into $\mathrm{ZnO}$ matrix. The photocatalytic measurements displayed that the PBA degradation efficiencies were of $64.19 \%$ and $100 \%$ for pure $\mathrm{ZnO}$ and $\mathrm{Mg}$-doped $\mathrm{ZnO}$ nanotaper photo-catalysts for 70 minutes under UV irradiation, respectively. Therefore, the degradation efficiency of $\mathrm{ZnO}$ nanotapers was significantly improved by $\mathrm{Mg}$ doping. Furthermore, the PBA degradation efficiencies were 43.40 $\%$ and $100 \%$ for pure and doped samples after 60 minutes under visible irradiation which indicates promotion of the degradation rate for $\mathrm{Mg}$-doped $\mathrm{ZnO}$ nanotapers in visible irradiation. $E_{\mathrm{g}}$ value was decreased for doped samplesdue tothe presence of $\mathrm{Mg}^{2+}$ inside the $\mathrm{Zn}^{2+}$ sites of the $\mathrm{ZnO}$ lattice which improve the charge separation. As a result, $\mathrm{Mg}$-doped $\mathrm{ZnO}$ nanotapers film not only photo-excited in the UV region but also its photocatalytic activity was delayed in the visible region.
\end{abstract}


Keywords: Mg-doped ZnO nanotapers; Electrochemical technique; Photocatalyst; Bisphenol A; Photodegradation

\section{$\underline{\text { FULL TEXT }}$}

(C) 2021 The Authors. Published by ESG (www.electrochemsci.org). This article is an open access article distributed under the terms and conditions of the Creative Commons Attribution license (http://creativecommons.org/licenses/by/4.0/). 